\title{
MiR-140-5p targets Prox1 to regulate the proliferation and differentiation of neural stem cells through the ERK/MAPK signaling pathway
}

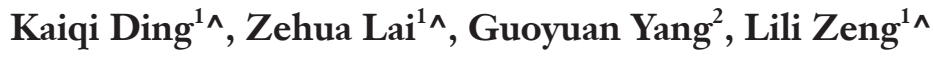 \\ ${ }^{1}$ Department of Neurology and Institute of Neurology, Ruijin Hospital, School of Medicine, Shanghai Jiao Tong University, Shanghai, China; \\ ${ }^{2}$ School of Biomedical Engineering, Shanghai Jiao Tong University, Shanghai, China \\ Contributions: (I) Conception and design: L Zeng, K Ding; (II) Administrative support: L Zeng, G Yang; (III) Provision of study materials or patients: \\ L Zeng, G Yang; (IV) Collection and assembly of data: K Ding, Z Lai; (V) Data analysis and interpretation: K Ding, Z Lai; (VI) Manuscript writing: \\ All authors; (VII) Final approval of manuscript: All authors. \\ Correspondence to: Lili Zeng, MD, PhD. Department of Neurology and Institute of Neurology, Ruijin Hospital, School of Medicine, Shanghai \\ Jiaotong University, No. 197 Ruijin second Road, Shanghai 200025, China. Email: 1lzeng@126.com.
}

Background: The expression of miR-140-5p increased in the brain tissue of a bilateral common carotid
artery ligation model, while the overexpression of miR-140-5p significantly decreased the number of
neurons. The luciferase report experiment in the previous study proved that miR-140-5p negatively
regulated one of the potential targets of Prospero-related homeobox 1 (Prox1). Therefore, we want to
investigate the effect of miR-140-5p on the proliferation and differentiation of neural stem cells (NSCs) and
the underlying mechanism.

Methods: Primary NSCs were extracted from pregnant ICR mice aged 16-18 days and induced to differentiate. After transient transfection with miR-140-5p mimic and inhibitor into NSCs, the cells were divided into five groups: blank, mimic normal control, mimic, inhibitor normal control, and inhibitor. Cell Counting Kit-8 (CCK-8) and 5-Bromo-2-deoxyUridine (BrDU), Ki-67 were used, and the diameter of neural spheres was measured to observe proliferation ability 48 h later. Doublecortin (DCX), glial fibrillary acidic protein (GFAP), microtubule-associated proteins 2 (MAP-2), synapsin I (SYN1), and postsynaptic density protein-95 (PSD-95) were stained to identify the effect of miR-140-5p on the differentiation ability of NSCs into neural precursor cells, astrocytes, and neurons and the expression of synapse-associated proteins. The expression of miR-140-5p, Prox1, p-ERK1/2, and ERK1/2 was analyzed by real time quantitative polymerase chain reaction (RT-qPCR) and Western blot analysis.

Results: While the expression of miR-140-5p decreased after NSC differentiation $(\mathrm{P}<0.05)$, the results of CCK-8, BrDU, and Ki-67 staining showed no significant difference in cell viability and the percentage of NSCs with proliferation ability $(\mathrm{P}>0.05)$. However, the neural spheres were shorter in the miR-140$5 \mathrm{p}$ overexpression group $(\mathrm{P}<0.05)$ and the expression of DCX, MAP2, synapsin I, and PSD-95 decreased, while the expression of GFAP increased after differentiation in the mimic group $(\mathrm{P}<0.05)$. In addition, the expression of Prox 1 decreased and the expression of $\mathrm{p}-\mathrm{ERK} 1 / 2$ protein increased $(\mathrm{P}<0.05)$, but the expression of ERK1/2 showed no significant difference $(\mathrm{P}>0.05)$ in the miR-140-5p overexpression group.

Conclusions: MiR-140-5p reduced the proliferation rate of NSCs, inhibited their differentiation into neurons, produced synapse-associated proteins, and promoted their differentiation into astrocytes. MiR-140$5 \mathrm{p}$ negatively regulated downstream target Prox1 and activated the ERK/MAPK signaling pathway.

Keywords: MicroRNA (miRNA); neural stem cells (NSCs); neurogenesis; Prox1; ERK/MAPK

^ ORCID: Kaiqi Ding, 0000-0001-5724-8144; Zehua Lai, 0000-0001-6982-4276; Lili Zeng, 0000-0001-8864-1280. 
Submitted Jan 31, 2021. Accepted for publication Apr 04, 2021.

doi: $10.21037 /$ atm-21-597

View this article at: http://dx.doi.org/10.21037/atm-21-597

\section{Introduction}

Cognitive impairment and depression are common complications after stroke, but effective diagnosis and treatment methods are still lacking and the pathogenesis is unclear (1). As a noncoding RNA, microRNA (miRNA) is a short RNA molecule with a length of 20-22 nucleotides which plays a role in post-transcriptional regulation, leading to the degradation of target mRNA and transcription inhibition (2). MiRNA could regulate the expression of multiple downstream target genes and was an excellent blood biomarker for diagnosing diseases (3). At present, miRNA has been reported to be involved in the pathogenesis of a variety of diseases, such as stroke, depression, and cognitive impairment (4). In the past few years, some studies have found that miRNA expression is abnormal in stroke patients.(5) More than $20 \%$ of miRNAs have changed in ischemic brains, which affect multiple physiological and pathological processes, such as proliferation, hematopoiesis, metabolism, immune function and depression after stroke.(6) MiRNAs can be used as biomarker for stroke prognosis, diagnosis and treatment. For example, miR-124 increased significantly 6 hours later and remained elevated 48 hours in the rat cerebral infarction model (7). Another study showed that there is a negative correlation between the brain ischemia and circulating miR-210 level (8).

Our previous studies on the miRNA expression profile demonstrated that miRNA-140-5p (miR-140-5p) was highly expressed in patients with depression after stroke, and its expression was positively related to the severity of depression (9). MiR-140-5p was also upregulated in a mouse bilateral common carotid artery ligation model (BCCAO) in vivo and its overexpression could inhibit neurogenesis in the hippocampus of BCCAO mice and aggravate cognitive impairment. A dual-luciferase experiment confirmed that miR-140-5p inhibited neurogenesis by downregulating its direct target Prospero-related homeobox 1 (Prox1). However, its specific mechanism in neurogenesis is still unknown.

Neural stem cells (NSCs) are self-renewing pluripotent stem cells that divide asymmetrically and can differentiate into neurons, astrocytes, and oligodendrocytes and only exist in two limited areas of the adult brain; the subventricular zone (SVZ) and the subgranular zone (SGZ) in the hippocampus (10). Neurogenesis encompasses multiple processes including neural stem cell proliferation, neuronal differentiation, and cell fate determination. The produced new neurons formed complex neuronal circuits after neurogenesis (11).

Neurogenesis originates from neural stem cells and produces new functional neurons, which is the basic process of embryonic neurodevelopment and plasticity of the adult brain. Neurogenesis starts from neuroepithelial cells (NE), which have ability of self-renewal and symmetrical division (12). Then neuroepithelial cells differentiate into radial glial cells (RG), which divide asymmetrically to produce a descendant RG cell and an intermediate neural progenitor cell (IPC). In the end, IPC can differentiate into neurons (13).

However, neurogenesis occurs at a very limited rate in healthy adult mammals and many neurons, astrocytes, and oligodendrocytes are damaged after acute ischemic stroke. Some pathological injuries such as cerebral ischemia can stimulate neurogenesis in the central nervous system and lead to increased proliferation, migration, and differentiation of NSCs and neural progenitors. Endogenous neurogenesis does not supply enough cells to repair neurological damage caused by major events such as stroke because of the limited renewal capacity and loss of neurocytes (14). Stem cell therapy may have a neuroprotective effect through the secretion of various neurotrophic factors and the replacement of damaged neurons (15). Therefore, exogenous NSC transplantation therapy is a possible way to recover neurological function after stroke $(16,17)$. However, the basic mechanism underlying the recovery and improvement in neurological function in stem cell therapy is still unclear at present and how to regulate NSC proliferation, differentiation, and cell fate determination is important for improving the efficiency of exogenous NSC transplantation (18).

Transcription factor Prox 1 is an miR-140-5p target and a key regulator of neurogenesis in the embryonic and adult central nervous system. By regulating the proliferation and differentiation of NSCs, it promotes cell cycle exit and differentiation into neurons and inhibits the 
Table 1 The sequences of miR-140-5p mimic and inhibitor

\begin{tabular}{|c|c|}
\hline Name & Sequence \\
\hline \multirow{2}{*}{$\begin{array}{l}\text { miR-140-5p mimic } \\
\text { normal control }\end{array}$} & 5'-UUGUACUACACAAAAGUACUG-3' \\
\hline & 5'-GUACUUUUGUGUAGUACAAUU-3' \\
\hline \multirow[t]{2}{*}{ miR-140-5p mimic } & 5'-CAGUGGUUUUACCCUAUGGUAG-3' \\
\hline & 5'-CUACCAUAGGGUAAAACCACUG-3' \\
\hline $\begin{array}{l}\text { miR-140-5p inhibitor } \\
\text { normal control }\end{array}$ & 5'-CAGUACUUUUGUGUAGUACAA-3' \\
\hline miR-140-5p inhibitor & 5'-CUACCAUAGGGUAAAACCACUG-3' \\
\hline
\end{tabular}

production of astrocytes (19). During adult hippocampus neurogenesis, Prox1 is necessary to maintain the differentiation and maturation of intermediate progenitor cells and glutamatergic central neurons (20). In addition, highly expressed Prox1 can activate the MAPK pathway to promote the growth and extension of glial cell neurites in Drosophila (21). Bioinformatics analysis also showed that miR-140-5p-predicted target genes were mainly enriched in the rat sarcoma/rapidly accelerated fibrosarcoma (Ras/Raf)-MEK-ERK mitogen-activated protein kinase (MAPK) signaling pathway, which was the key cell-signaling pathway controlling axon outgrowth (22).

Therefore, it was hypothesized that miR-140-5p could regulate NSC function via targeting Prox1 and regulating the ERK/MAPK signaling pathway. The key signal axis that regulated neurogenesis was discovered, which helped in promoting the proliferation and differentiation of NSCs and improving the effectiveness of stem cell therapy to treat central nervous system diseases in the brain. We presented the following article in accordance with the Animal Research: Reporting In Vivo Experiment (ARRIVE) reporting checklist (available at http://dx.doi.org/10.21037/ atm-21-597).

\section{Methods}

All animal experiments were performed in accordance with the guidelines for animal care and the research protocol for this study was approved by the Institutional Animal Care and Use Committee of Shanghai Jiao Tong University, Shanghai, China.

\section{Cell culture and induced differentiation}

Fetal mice were taken from the uterus of institute of cancer research (ICR) strain mice aged E16-18 days (Leigen, Shanghai, China). Brain tissue was digested into single cells in suspension with 1:1 trypsin-(EDTA) (Gibco, CA, USA) and phosphate buffer saline (PBS) after peeling off the meninges and bleeding points from the brain. The cells were then cultured with a seeding density of $30 \times 10^{5}$ cells $/ \mathrm{mL}$. The NSC culture medium included 97\% DMEM/F12 (Gibco, CA, USA), 1\% B27 (Gibco, CA, USA), $20 \mathrm{ng} / \mathrm{mL}$ epidermal growth factor (EGF) (Peprotech, NJ, USA), $20 \mathrm{ng} / \mathrm{mL}$ basic fibroblast growth factor (bFGF) (Peprotech, NJ, USA), $1 \%$ GlutaMAX (Gibco, CA, USA), and 1\% penicillin/streptomycin (P/S) (Gibco). NSCs gradually proliferated and converged into neural spheres with different diameters over time when cultured in a suspension and were passaged with Accutase cell dissociation reagent (Gibco) for 10 min approximately 4 days later with the centrifuge tube shaken every $2 \mathrm{~min}$. The cells were then seeded on a culture plate coated with $0.1 \mathrm{mg} / \mathrm{mL}$ Polylysine (PDL) (Sigma, USA) after digestion on the seventh day following isolation and single NSCs adhered to the culture plate and started differentiating. The induced differentiation medium contained 97\% Neurobasal Medium (Gibco, CA, USA), 2\% B27, 1\% Glutamax (Gibco, CA, USA), and 1\% $\mathrm{P} / \mathrm{S}$. NSCs gradually protruded into longer neurites and their cell morphology changed during differentiation.

\section{Cell transfection}

Cells in the MiR-140-5p mimic normal control (nc), mimic, inhibitor, and inhibitor normal control (nc) groups (Sangong, Shanghai, China) with green fluorescence (GFP) were separately diluted with NSC culture medium and mixed with Lipofectamine 2000 (Thermofisher, CA, USA) for $20 \mathrm{~min}$. Their final concentrations were 50, 50, 100 , and $100 \mathrm{nM}$, respectively. The blank group were then transfected with Lipofectamine 2000 solution only (Thermofisher, CA, USA), while mice in the other four groups were transfected with miR-140-5p mimic nc, mimic, inhibitor, and inhibitor nc, respectively with the medium changed after 6-h transient transfection. GFP was observed through an inverted fluorescence microscope, and RNA and protein were extracted to perform RT-qPCR and Western blot analysis $48 \mathrm{~h}$ later. The sequences of miR-140-5p mimic and inhibitor were as follows (Table 1).

\section{Immunofluorescence}

NSCs were seeded on the cell slide after being coated 
Table 2 The list of antibodies used in this study

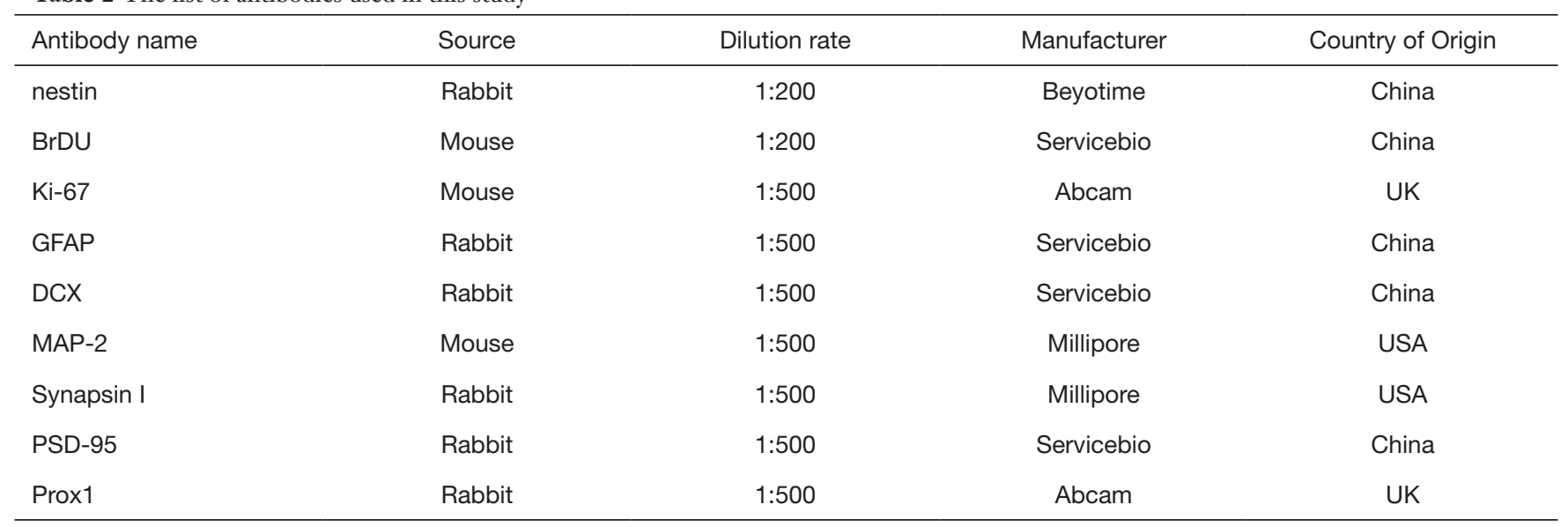

with Poly-D-lysine (PDL) (Sigma) for $6 \mathrm{~h}$ and each 24-well plate was inoculated with about $1 \times 10^{5}$ NSCs. Immunofluorescence staining was performed $48 \mathrm{~h}$ later. First, the cells were fixed with $4 \%$ paraformaldehyde for 10 min at room temperature, incubated with $0.3 \%$ Triton X-100 to permeabilize for $10 \mathrm{~min}$, and blocked with $10 \%$ bovine serum albumin (BSA) at room temperature for $1 \mathrm{~h}$. Cells were then incubated with primary antibodies including polyclonal rabbit nestin (1:200, Beyotime, Shanghai, China), mouse 5-Bromo-2-deoxyUridine(BrDU) (1:200, Servicebio, Wuhan, China), mouse Ki-67 (1:500, Abcam, UK), rabbit glial fibrillary acidic protein (GFAP) (1:500, Servicebio), rabbit Doublecortin (DCX) (1:500, Servicebio), mouse Microtubule-associated proteins 2 (MAP-2) (1:500, Millipore, MA, USA), rabbit synapsin I (1:500, Millipore), rabbit Postsynaptic density protein-95 (PSD-95) (1:500, Servicebio) and Prox1 (1:500, Abcam, $\mathrm{UK})$, for $12-14 \mathrm{~h}$ at $4{ }^{\circ} \mathrm{C}$ on a shaker. The secondary antibody was Alexa 488/555-conjugated donkey anti-rabbit/ mouse (1:500, Beyotime). Finally, $10 \mu \mathrm{L}$ of the mounting medium containing 4,6-diamino-2-phenyl indole (DAPI) was added to observe the result under a laser scanning confocal microscope, and images were taken. Every time new reagent was added, the cells were washed with PBS three times for $5 \mathrm{~min}$.

After BrDU staining, DNA hydrolysis was performed before the cells were blocked and the cells were incubated with $1 \mathrm{M} \mathrm{HCl}$ for $10 \mathrm{~min}$ at room temperature, $2 \mathrm{M} \mathrm{HCl}$ for $20 \mathrm{~min}$, and $0.1 \mathrm{M}$ sodium borate buffer $(\mathrm{pH} 8.5)$ for $30 \mathrm{~min}$. The ratio of $\mathrm{BrDU}^{+}$and $\mathrm{Ki}-67^{+}$cells to the total $\mathrm{DAPI}^{+}$cells was calculated to evaluate the proportion of NSCs with proliferation ability in different groups. In addition, the mean fluorescence intensity of DCX, MAP-2, and GFAP was measured with ImageJ software to detect any difference in expression in the five groups. The list of antibodies used in this study is as follows (Table 2).

\section{Cell Counting Kit-8 (CCK-8) assay}

The cells were seeded in a 96-well plate coated with PDL for $6 \mathrm{~h}$ with each group having five repeated wells with 2,000 cells/well. After the cells adhered to the undersurface, they were transfected with miR-140-5p mimics and inhibitors. Then, $90 \mu \mathrm{L}$ of NSC culture medium and $10 \mu \mathrm{L}$ of CCK-8 aliquot were mixed, and NSCs were incubated for $1.5 \mathrm{~h}$ at $37^{\circ} \mathrm{C}$ after 48 -h transfection. The absorbance was detected at $450 \mathrm{~nm}$ in the five groups and the cell viability was calculated using the following formula: (experiment group - blank well)/(control well - blank well) $\times 100 \%$. The blank well contained no cells. GraphPad Prism 8 software was then used to draw histograms and perform analysis of variance (ANOVA).

\section{$R T-q P C R$}

The cells were seeded in a six-well plate coated with PDL for $6 \mathrm{~h}$ with each cell containing $2 \times 10^{5}$ cells. TRIzol reagent (Invitrogen, CA, USA) was used to extract RNA after 48-h transfection. The RNA concentration was determined with a NanoDrop 2000 spectrophotometer (Thermofisher, CA), and $500 \mathrm{ng}$ RNA from each group was taken to perform reverse transcription using a miRNA First Strand cDNA Synthesis kit (Vazyme, Nanjing, China). Polymerase chain reaction (PCR) amplification was performed using a real- 
Table 3 The sequences of primers

\begin{tabular}{ll}
\hline Primer name & Sequence \\
\hline miR-140-5p reverse transcription & 5'-GTCGTATCCAGTGCAGGGTCCGAGGTATTCGCACTGGATACGACCTACCA-3' \\
miR-140-5p forward & 5'-CGCGCAGTGGTTTTACCCTA-3' \\
U6 reverse transcription & 5'-AACGCTTCACGAATTTGCGT-3' \\
U6 forward & 5'-CTCGCTTCGGCAGCACA-3' \\
U6 reverse & 5'-AACGCTTCACGAATTTGCGT-3' \\
\hline
\end{tabular}

time RT-PCR system (7900 HT, ABI, CA, USA) with a miRNA Universal SYBR qPCR Master Mix kit (Vazyme). The miR-140-5p relative expression was calculated using the $2^{-\Delta \Delta \mathrm{CT}}$ formula with U6 as the internal reference gene and GraphPad Prism 8 software was used to draw histograms and perform ANOVA. The sequences of primers were as follows (Table 3).

\section{Western blot analysis}

Cells were seeded in a six-well plate, with $1 \times 10^{6}$ cells/well. Proteins were collected with RIPA lysis buffer (Sigma), supplemented with $1 \times$ protease inhibitor cocktail (Sigma), $1 \times$ Phenylmethylsulfonyl fluoride (PMSF) (Thermofisher), and $1 \times$ phosphatase inhibitor (Thermofisher). A bicinchoninic acid (BCA) Protein Quantitative Kit (Beyotime) was used to detect the protein concentration. The protein sample amount in each group was $30 \mu \mathrm{g}$ for electrophoresis at $120 \mathrm{~V}$ (Bio$\mathrm{Rad}, \mathrm{CA}, \mathrm{USA}$ ) and $0.2-\mu \mathrm{m}$ polyvinylidenefluoride (PVDF) membrane was used for $1.5 \mathrm{~h}$ at $300 \mathrm{~mA}$. The membranes were blocked with $10 \%$ BSA, and incubated with primary antibodies, such as polyclonal rabbit GAPDH $(1: 2,000$, Servicebio), Prox1 (1:2,000, Abcam, UK), p-ERK1/2 (1:2,000, CST, MA, USA), and ERK1/2 (1:2,000, CST). Subsequently, the membranes were incubated with the anti-rabbit HRP-conjugated secondary antibody $(1: 3,000$, Servicebio) for $1 \mathrm{~h}$ and then reacted with enhanced chemiluminescence liquid (Beyotime). The results were observed using a Chemiluminescence Imager (Bio-Rad), and the relative intensity was calculated using the Image J software (NIH, MD, USA) using GAPDH as the internal control. GraphPad Prism 8 software was used to draw histograms and perform ANOVA.

\section{Statistical analysis}

Images were processed, the cells counted, and the average fluorescence intensity was measured using Image J software. GraphPad Prism 8 software was used to draw histograms and perform the Student $t$ test and one-way ANOVA was used to analyze the differences between the five groups. SPSS version 26 was used to perform the StudentNewman-Keuls (SNK) test when multiple groups were compared after transfection in different groups. All data were expressed as mean \pm standard deviation and differences were considered significant at $\mathrm{P}<0.05$.

\section{Results}

\section{Experimental timeline}

Primary NSCs were isolated from mice after transfecting miR-140-5p mimic and inhibitor into NSCs. The proliferation ability and differentiation into astrocytes, neurons, and synaptic-associated proteins were examined in different groups. The mechanism by which miR-140-5p influenced the potential target of transcription factor Prox1 and ERK/MAPK signaling pathway was also studied. The experimental timeline of this study is showed in Figure 1.

\section{NSC culture, identification, and differentiation in vitro}

NSCs were isolated from pregnant ICR mice aged 16-18 days. As NSCs gradually proliferated, they accumulated and became neural spheres with different diameters and the bright-field image is shown in the top left corner of Figure $2 \mathrm{~A}$ and one generation of cells were passaged every 3-4 days. The original NSC culture medium was aspirated, and a new induced differentiation medium was added to the culture plate. About 3 days later, some NSCs differentiated into neural precursor cells and about 7 days after differentiation, they became neurons and astrocytes. The cell morphology was observed within 7 days during the differentiation process (Figure $2 A$ ).

The RNA was also extracted to determine the expression 


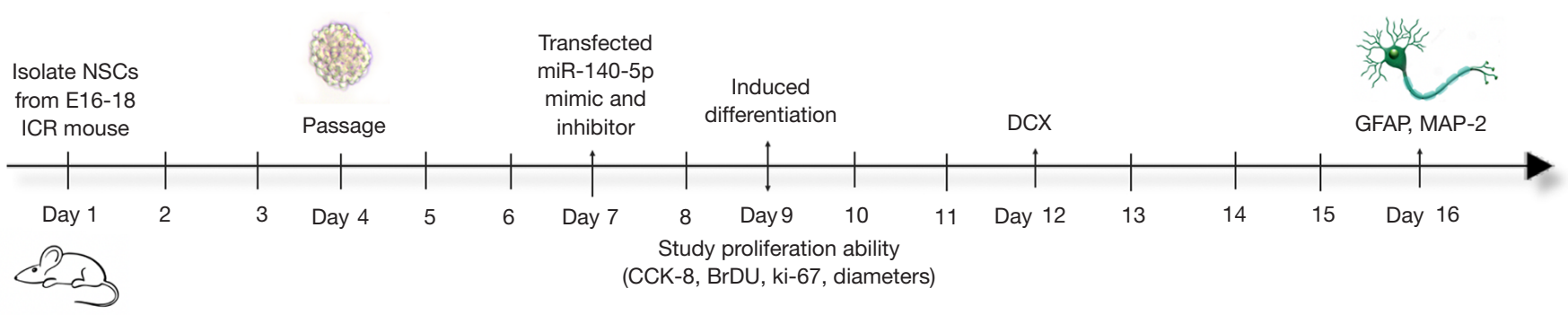

Figure 1 Experimental timeline of this study. Neural stem cells (NSCs) were passaged on the fourth day after isolation and transfected with 140-5p mimics and inhibitors on the seventh day. On the ninth day, some NSCs were taken to analyze the proliferation ability in each group. Protein and RNA samples were also extracted for Western blot analysis and RT-qPCR. The remaining NSCs were induced to differentiate on the ninth day. The cells were stained with doublecortin (DCX) on the 12th day, that is, after 3 days of differentiation. Microtubuleassociated proteins 2 (MAP-2), glial fibrillary acidic protein (GFAP), Synapsin I, and postsynaptic density protein-95 (PSD-95) were stained on the 16th day, that is, after 7 days of differentiation.

of miR-140-5p at four different time points during this process. The expression of miR-140-5p decreased compared with that before differentiation $(\mathrm{P}<0.05)$, but it remained basically unchanged thereafter (Figure $2 B$ ).

Nestin is a cytoskeleton protein and the marker of NSCs. $\mathrm{P}_{2}$ NSCs were removed and inoculated on cell slides for DAPI staining and nestin immunofluorescence (Figure 2C) and the bright-field co-staining of DAPI confirmed the cells were NSCs. Doublecortin (DCX) staining was successfully performed after 3 days of differentiation. Glial fibrillary acidic protein (GFAP) and microtubule-associated proteins 2 (MAP-2) staining was performed after 7 days of differentiation and were the specific markers of neural precursor cells, astrocytes, and neurons (Figure 2C).

\section{Transient transfection of miR-140-5p into NSCs}

MiR-140-5p mimic and inhibitor with green fluorescent (GFP) were transfected into NSCs for 48 hours and green fluorescence was seen under the microscope (Figure $3 A$ ). RNA samples were also extracted from the five groups to perform RT-qPCR, confirming that miR-140-5p expression was upregulated in the mimic group, while miR-140$5 \mathrm{p}$ expression was downregulated in the inhibitor group $(\mathrm{P}<0.05)$. No significant difference was observed among the other three groups $(\mathrm{P}>0.05)$ (Figure $3 B)$. The co-localization of the bright field and green fluorescence of NSCs indicated successful transfection (Figure 3C).

\section{MiR-140-5p reduced the proliferation rate, not the ratio of NSCs}

NSCs have self-renewal ability through asymmetrical division and differentiation into neurons and glial cells (15). Four different methods were used to examine the proliferation ability of NSCs: 5-Bromo-2-deoxyUridine (BrDU), Ki-67, CCK-8, and neural dynamic analysis. BrDU is a thymine nucleotide analog that can replace thymidine, while Ki-67 is a related antigen of proliferated cells and both are closely associated with cell mitosis and can be used as markers of proliferation ability.

As a result, BrDU and Ki-67 immunofluorescence was performed in the five groups after 48 -h transfection as this was the time when transfected microRNA was highly expressed in cells. $\mathrm{BrDU}^{+}$and $\mathrm{Ki}-67^{+}$cells accounted for approximately $90 \%$ of the total, implying that most $\mathrm{DAPI}^{+}$ cells were NSCs with proliferation ability. The positively stained cells were then counted, and the statistical results showed that there was no significant difference in the proportion of $\mathrm{BrDU}^{+}$and $\mathrm{Ki}-67^{+}$cells $(\mathrm{P}>0.05)$. Further, MiR-140-5p expression did not affect the proliferation ratio of NSCs (Figure 4A,B).

The results of the CCK- 8 experiment showed no significant difference in the cell viability of the five groups after statistical analysis $(\mathrm{P}>0.05)$, implying that miR-140-5p did not affect the cell viability of NSCs (Figure 4C).

The diameters of neural spheres were measured 0,12 , 24 , and $48 \mathrm{~h}$ after transfection using Image J software. The bigger neural spheres represented faster proliferation 

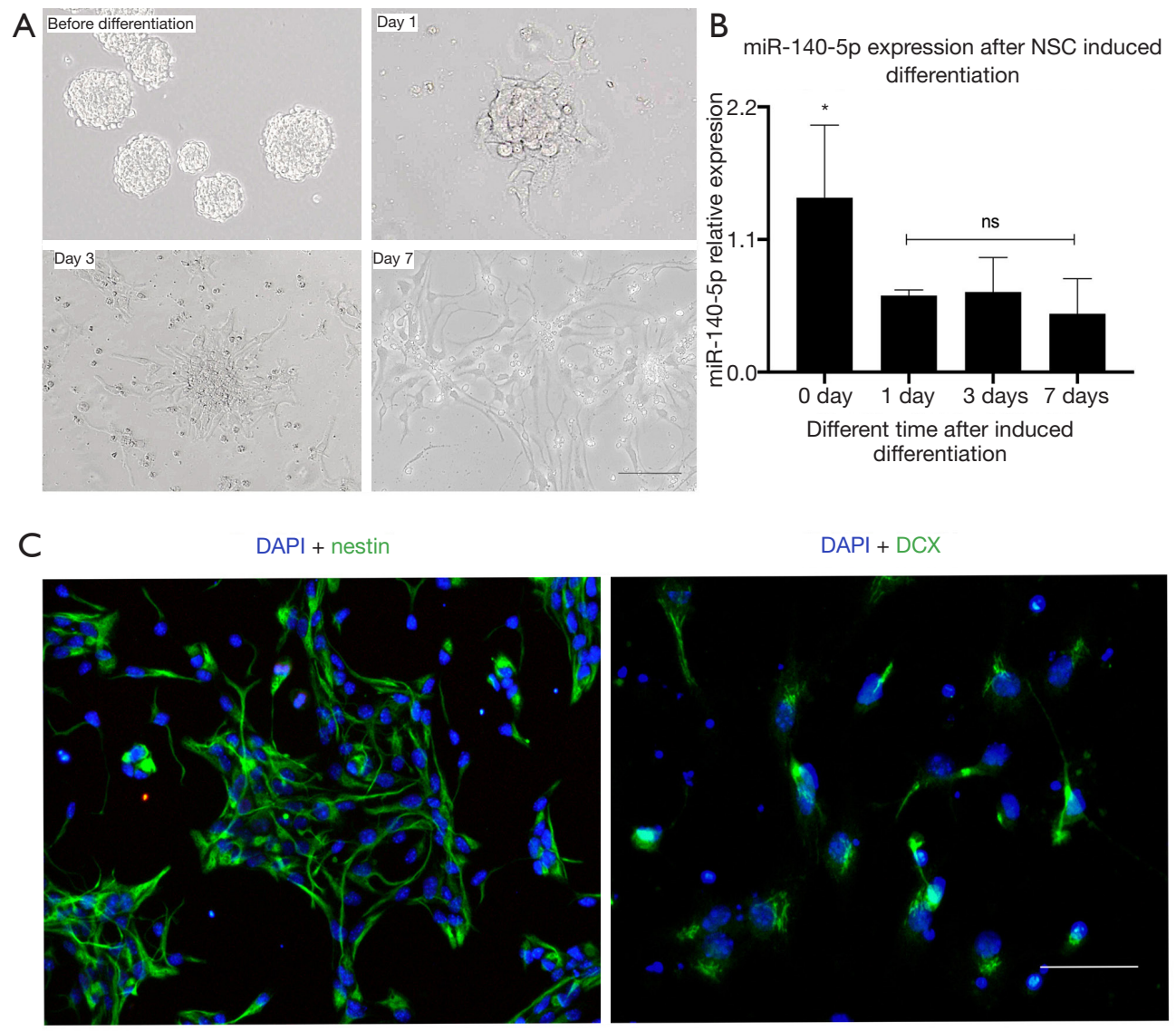

$\mathrm{DAPI}+\mathrm{GFAP}$

$\mathrm{DAPI}+$ map-2
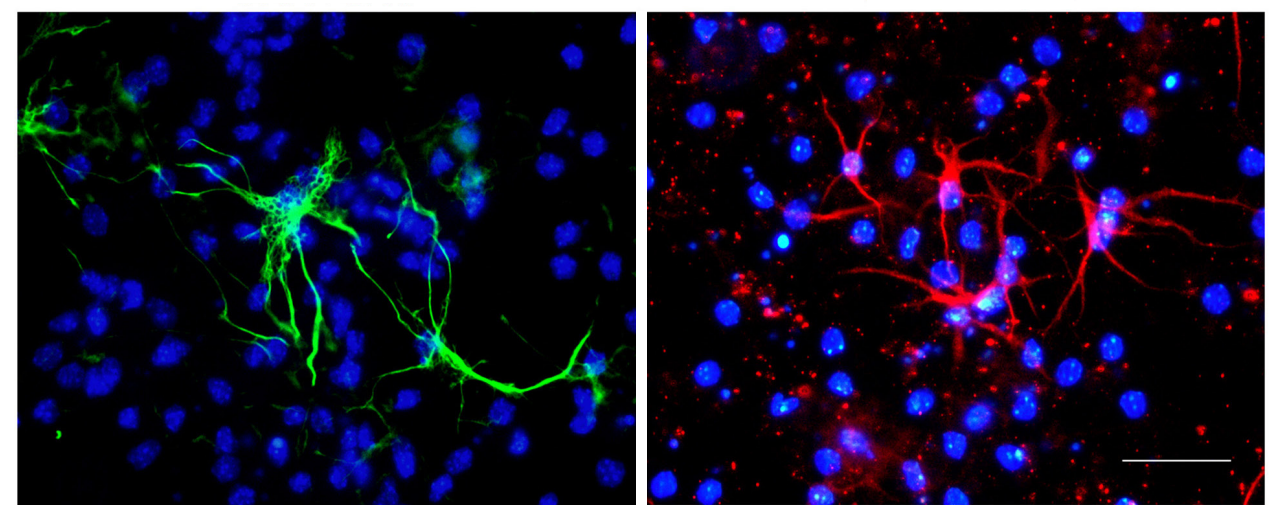

Figure 2 Neural stem cell (NSC) culture, identification, and differentiation in vitro. (A) Change in cell morphology within 7 days during the differentiation process. Bar $=50 \mu \mathrm{m}$. (B) Expression of miR-140-5p after NSC differentiation. (C) Identification of NSCs, neural precursor cells, astrocytes, and neurons after differentiation, using nestin (green), glial fibrillary acidic protein (GFAP) (green), doublecortin (DCX) (green), and MAP-2 (red) markers. Bar $=50 \mu \mathrm{m}$. Data are presented as the mean $\pm \mathrm{SEM}$ (standard error of mean) $\left({ }^{*} \mathrm{P}<0.05\right)$.

because single NSCs gathered when they were cultured in suspension (Figure 4D). No difference was found $0 \mathrm{~h}$ after transfection, but after 12-h transfection, the diameters were found to be different. The diameters were also shorter 12,
24 , and $48 \mathrm{~h}$ after transfection in the mimic group $(\mathrm{P}<0.05)$. The other four groups showed no statistical discrepancy, indicating that miR-140-5p influenced the proliferation rate of NSCs (Figure 4E). 

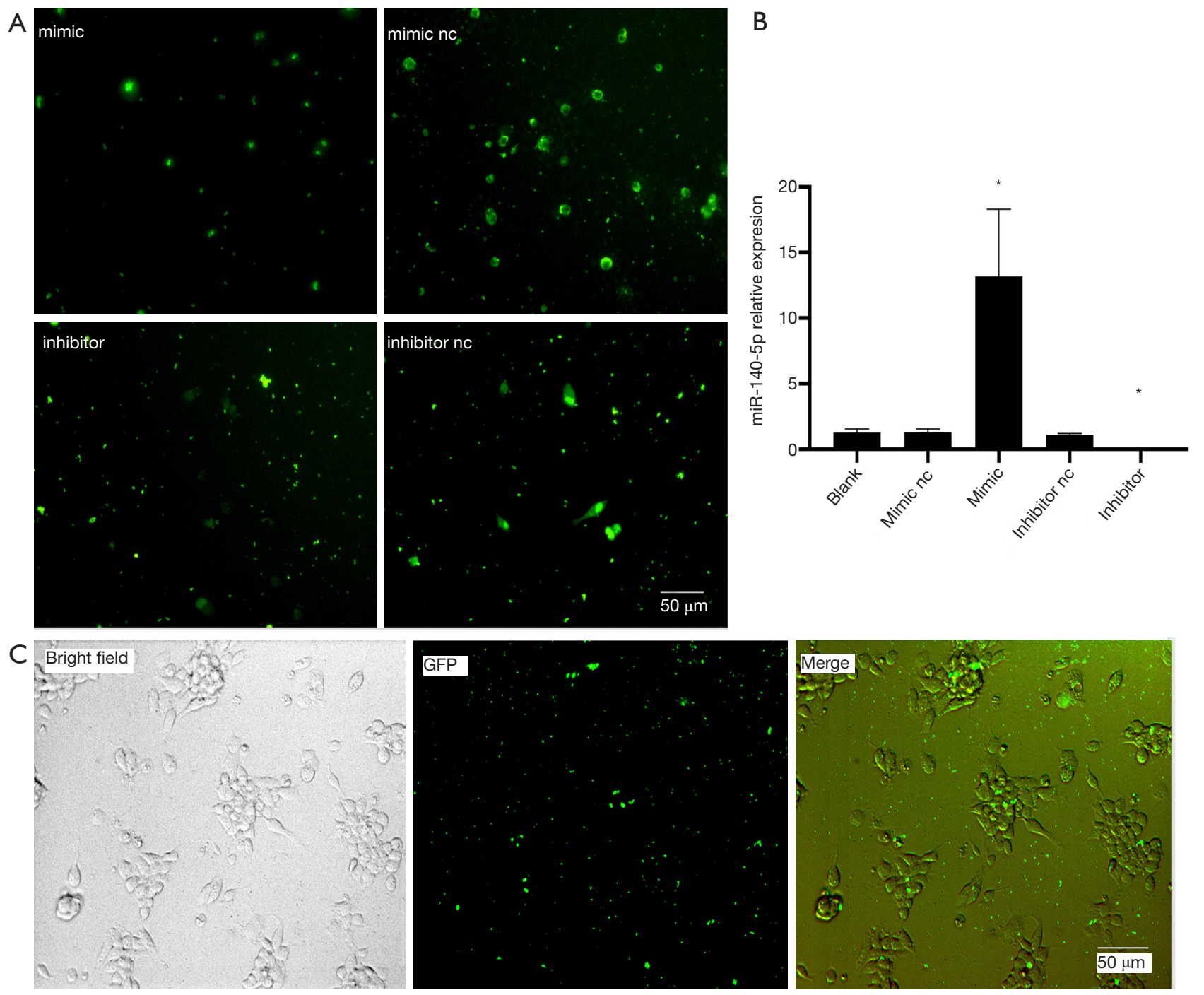

Figure 3 Transient transfection of miR-140-5p into neural stem cells (NSCs). (A) Green fluorescence images of four groups after 48-h transfection. (B) MiR-140-5p expression in the five groups after 48-h transfection. Data are presented as the mean $\pm \mathrm{SEM}\left({ }^{*} \mathrm{P}<0.05\right)$. (C) Co-localization of the bright field and green fluorescence images of NSCs. Bar $=50 \mu \mathrm{m}$. Data are presented as the mean $\pm \mathrm{SEM}\left({ }^{*} \mathrm{P}<0.05\right)$.

\section{MiR-140-5p inbibited NSC differentiation into neurons, but promoted differentiation into astrocytes}

The differentiation ability of NSCs was then evaluated. DCX, MAP-2, and GFAP were the markers of neural precursor cells, neurons, and astrocytes, respectively. After digestion, NSCs were seeded on the cell slides coated with PDL after $6 \mathrm{~h}$, while DCX staining was performed after 3 days of differentiation and, MAP-2 staining was conducted after 7 days. The average fluorescence intensity was used to analyze the expression and showed DCX and MAP-2 staining intensity significantly reduced in the mimic group or the miR-140-5p overexpressed group $(\mathrm{P}<0.05)$, while it increased in the inhibitor group or miR-140-5p downregulated group $(\mathrm{P}<0.05)$. The other three groups showed no obvious difference $(\mathrm{P}>0.05)$, indicating that miR140-5p inhibited NSC differentiation into neural precursor cells and neurons (Figure $5 A, B$ ).

GFAP staining was also performed and the result was contrary to that for DCX and MAP-2. The expression of GFAP in the mimic group significantly increased $(\mathrm{P}<0.05)$, while it reduced in the inhibitor group compared with the other groups $(\mathrm{P}<0.05)$, implying that miR-140-5p promoted NSC differentiation into astrocytes (Figure 5C). 

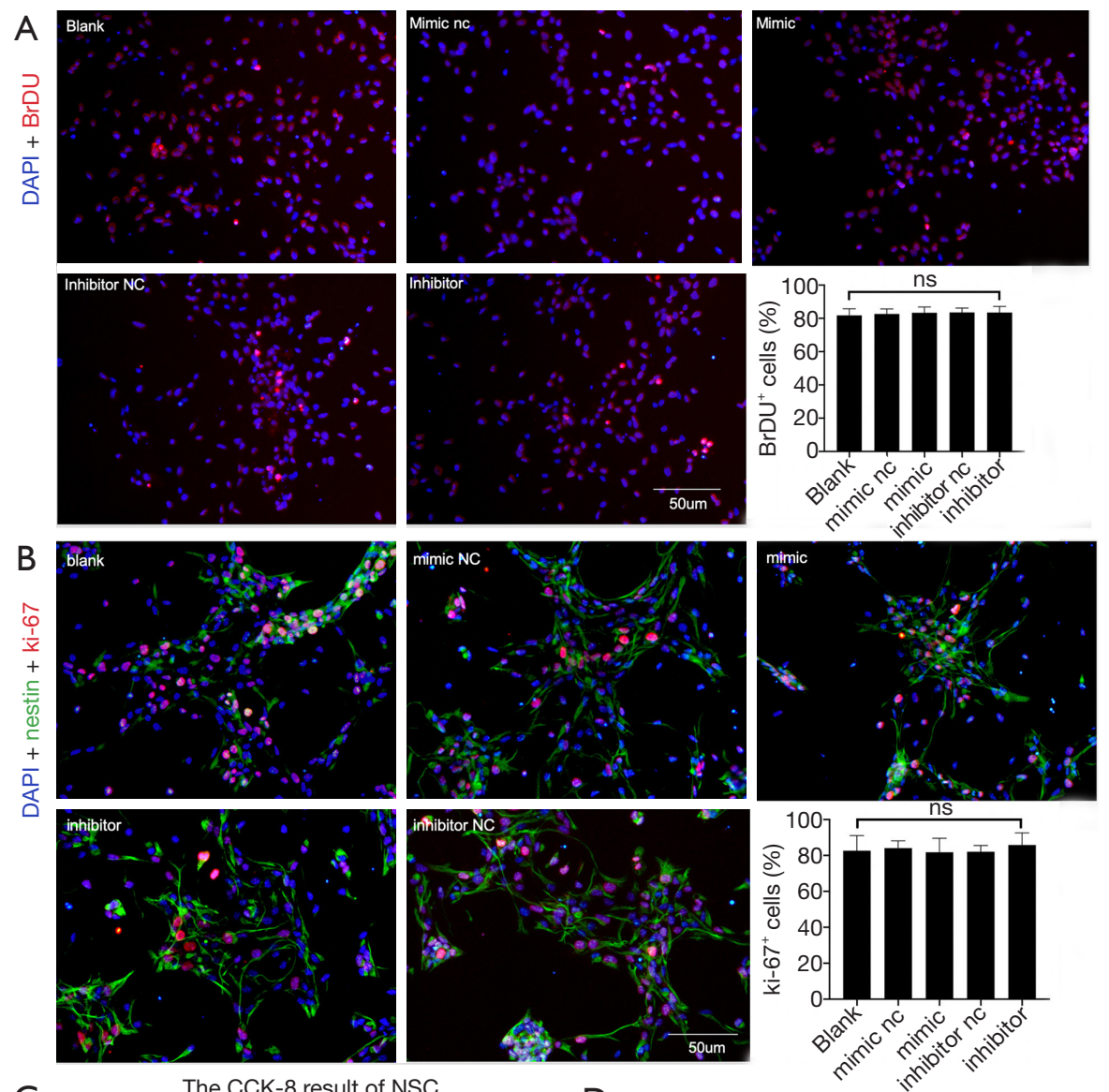

C
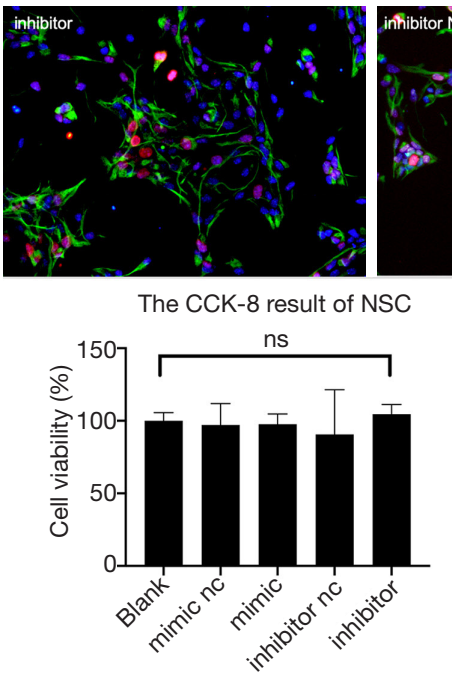

$\mathrm{D}$

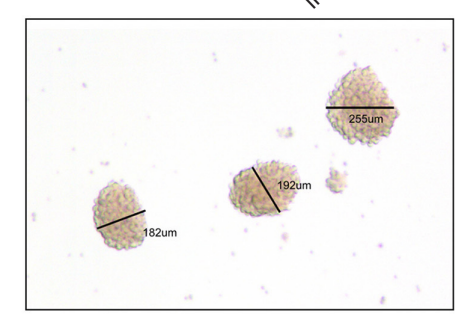

$\mathrm{E}$

The diameter of NSC during proliferation

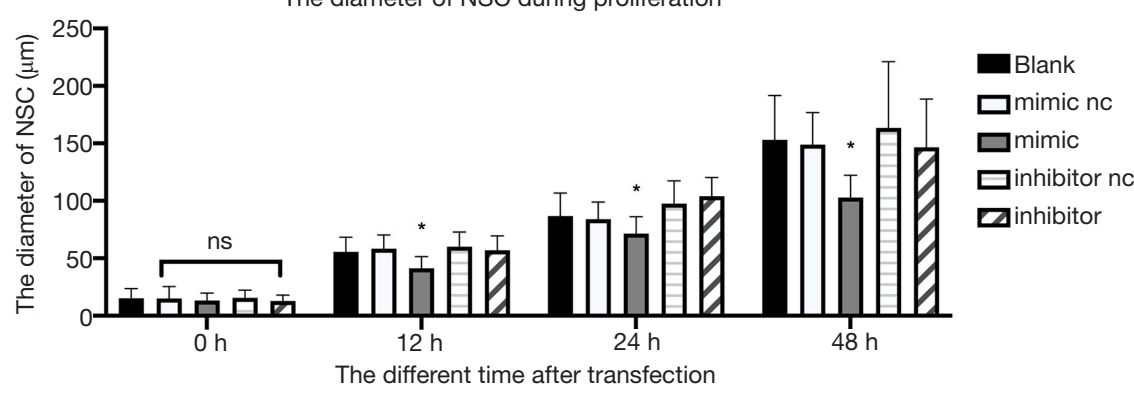

Figure 4 Overexpression of miR-140-5p affected the proliferation rate, not the ratio of neural stem cells (NSCs). (A) 4,6-diamino-2-phenyl indole (DAPI) (blue) + 5-Bromo-2-deoxyUridine (BrDU) (red) immunofluorescence staining in the five groups. (B) DAPI (blue) + nestin (green) + ki-67 (red) immunofluorescence staining in the five groups. (C) CCK-8 result in the five groups. (D) Method used to measure the diameter of neural spheres. (E) Comparison of neural sphere diameters 12, 24, and $48 \mathrm{~h}$ after transfection in the five groups. Data are presented as the mean $\pm \operatorname{SEM}\left({ }^{*} \mathrm{P}<0.05\right)$. Bar $=50 \mu \mathrm{m}$. 

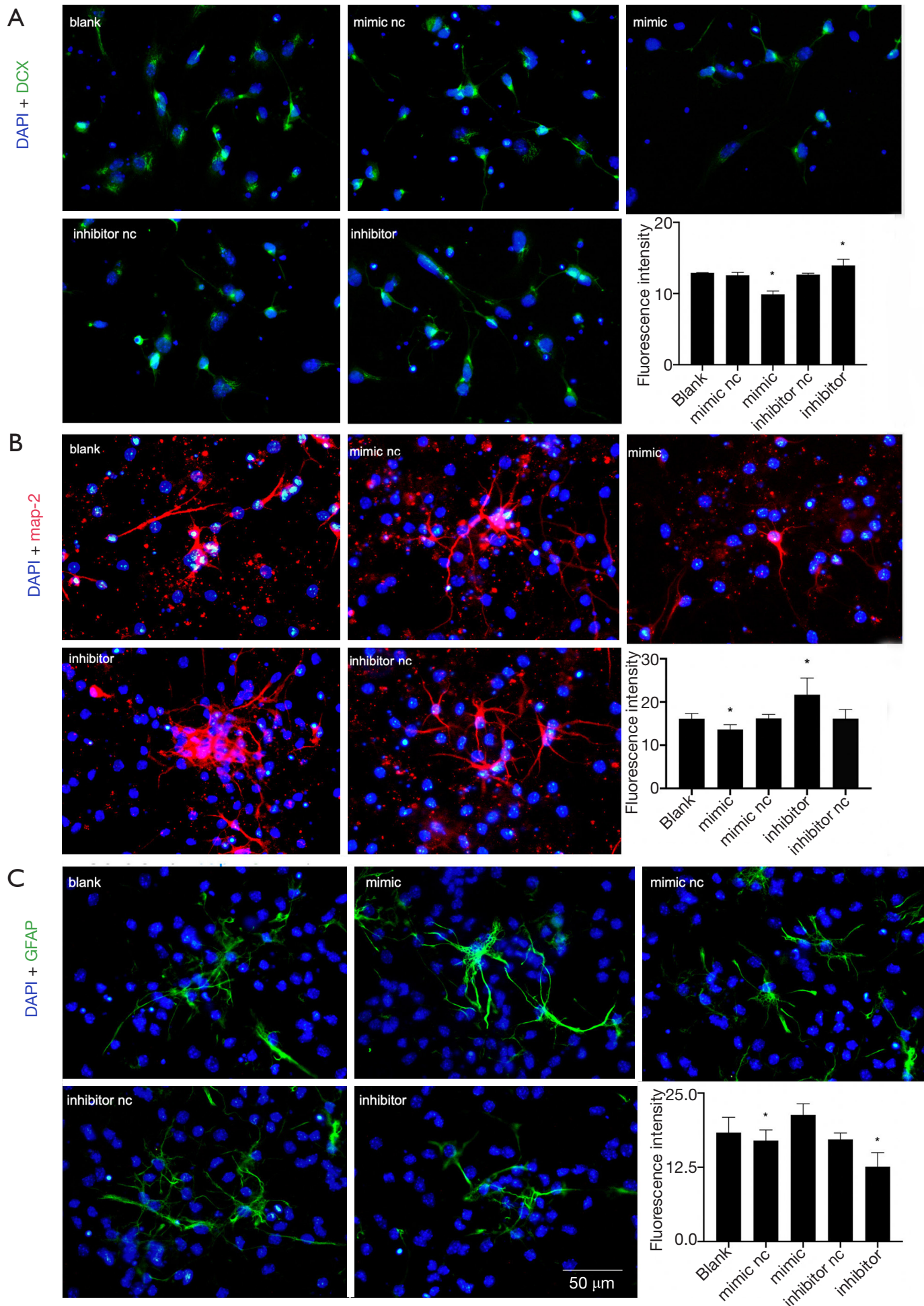

Figure 5 Overexpression of miR-140-5p inhibited differentiation into neurons and promoted the differentiation of neural stem cells (NSCs) into astrocytes. (A) 4,6-diamino-2-phenyl indole (DAPI) (blue) and doublecortin (DCX) (green) staining of NSCs after 7 days of differentiation in the five groups. (B) DAPI (blue) and map-2 (red) immunofluorescence of NSCs after differentiation. (C) DAPI (blue) and glial fibrillary acidic protein (GFAP) (green) result after 7 days of differentiation in the five groups. Bar $=50 \mu \mathrm{m}$. Data are presented as the mean $\pm \operatorname{SEM}\left({ }^{*} \mathrm{P}<0.05\right)$. 


\section{MiR-140-5p inbibited the expression of synapse-associated proteins after differentiation}

The structure and function of synapses are the basis of learning and memory. Synapses participate in the formation and maintenance of synaptic connections and regulate the release of neurotransmitters in the central nervous system. Therefore, in addition to the three markers previously mentioned, the immunofluorescence of Synapsin I and postsynaptic density protein-95 (PSD-95) was also performed 7 days after differentiation and found to be presynaptic and postsynaptic membrane proteins, respectively. The percentage of positive cells was calculated in the five groups and showed percentages of Synapsin $\mathrm{I}^{+}$ and PSD $-95^{+}$cells significantly decreased in the mimic group, but obviously increased in the inhibitor group $(\mathrm{P}<0.05)$. The remaining three control groups showed no significant difference $(\mathrm{P}>0.05)$ (Figure $6 A, B)$. It was inferred that the overexpression of miR-140-5p inhibited the generation of synapse-associated proteins.

\section{MiR-140-5p inhibited the downstream target of transcription factor Prox 1}

The potential mechanism of miR-140-5p was explored. Generally, the microRNA 5'-UTR sequence made of two to eight nucleotides is complementary to the 3'-UTR of the target gene, playing a role in post-transcriptional regulation and causing mRNA shear degradation and translation inhibition (16). In a previous study, the dual luciferase reporter proved that Prox 1 was one of the potential downstream targets of miR-140-5p (6) and many researchers have reported the influence of Prox1 on neurogenesis, which served as one of the targets of miR-140-5p (11).

After 48-h transfection with miR-140-5p mimic and inhibitor, Prox 1 immunofluorescence and Western blot analysis were performed and the results showed that the number of Prox $1^{+}$NSCs was much less in the mimic group. However, the number of Prox $1^{+}$NSCs was much more in the inhibitor group $(\mathrm{P}<0.05)$ (Figure $7 A)$. Six nucleotides in 3'-UTR of Prox1 were complementary to the miR-140-5p sequence (Figure 7B). The result of Western blot analysis was similar to that of IF, supporting the contention that miR-140$5 p$ negatively regulated Prox1 $(\mathrm{P}<0.05)$ (Figure $7 C)$.

\section{MiR-140-5p activated the ERK/MAPK signaling pathway}

The relationship between miR-140-5p and ERK/MAPK was explored based on the findings of Prox 1 in the MAPK pathway in Drosophila (13) and the bioinformatics analysis of the miR-140-5p and Ras/Raf-MEK-ERK MAPK pathway (5). MAPK is a group of highly conserved serine/ threonine protein kinases related to cell growth and differentiation. This signaling pathway includes three levels of signal transmission: MAPK, MAPK kinase (MEK or MKK), and MAPK kinase kinase (MEKK or MKKK).

The expression of p-Erk1/2 and Erk1/2 were evaluated using IF and Western blot analysis. The protein samples were collected $48 \mathrm{~h}$ after transfection as described earlier. The fluorescence intensity of p-Erk1/2 increased significantly in the mimic group but was reduced in the inhibitor group compared with the control group $(\mathrm{P}<0.05)$ (Figure $8 A$ ). Western blot analysis result was consistent with that of IF, but no significant difference was noted in the ERK1/2 expression between groups $(\mathrm{P}>0.05)$ (Figure 8B).

\section{Discussion}

The present study demonstrated that miR-140-5p inhibited NSC proliferation, inhibited their differentiation into neurons, produced synapse-associated proteins, and promoted differentiation into astrocytes. MiR-140-5p also negatively regulated downstream target Prox1 and activated the ERK/MAPK signaling pathway. This study was novel in revealing the underlying mechanism of miR-140-5p in regulating NSC function and provides a theoretical basis for miR-140-5p regulating neurogenesis and treating cognitive and affective disorders after nervous system disease for the following reasons.

Firstly, the expression of miR-140-5p reduced after differentiation and then basically remained unchanged during the differentiation process. Later, the proliferation of NSCs slowed down in the miR-140-5p overexpression group, implying that miR-140-5p affected the self-division ability of NSCs and reduced their numbers in the brain. In the adult brain, the proliferation ability of NSCs is inherently limited and elevated miR-140-5p expression after cerebral ischemia inhibited the proliferation of NSCs, which was harmful to disease recovery (23). Secondly, while miR-140-5p inhibited NSC differentiation into neurons, it promoted their differentiation into astrocytes. In the embryonic and early postnatal stages, most cells can divide quickly, but in adult mammals, the cell proliferation is limited within a few stem cells. Activated NSCs in the brain can self-renew to maintain a stem cell bank and differentiate into neurocytes for tissue repair. NSCs are the main source 

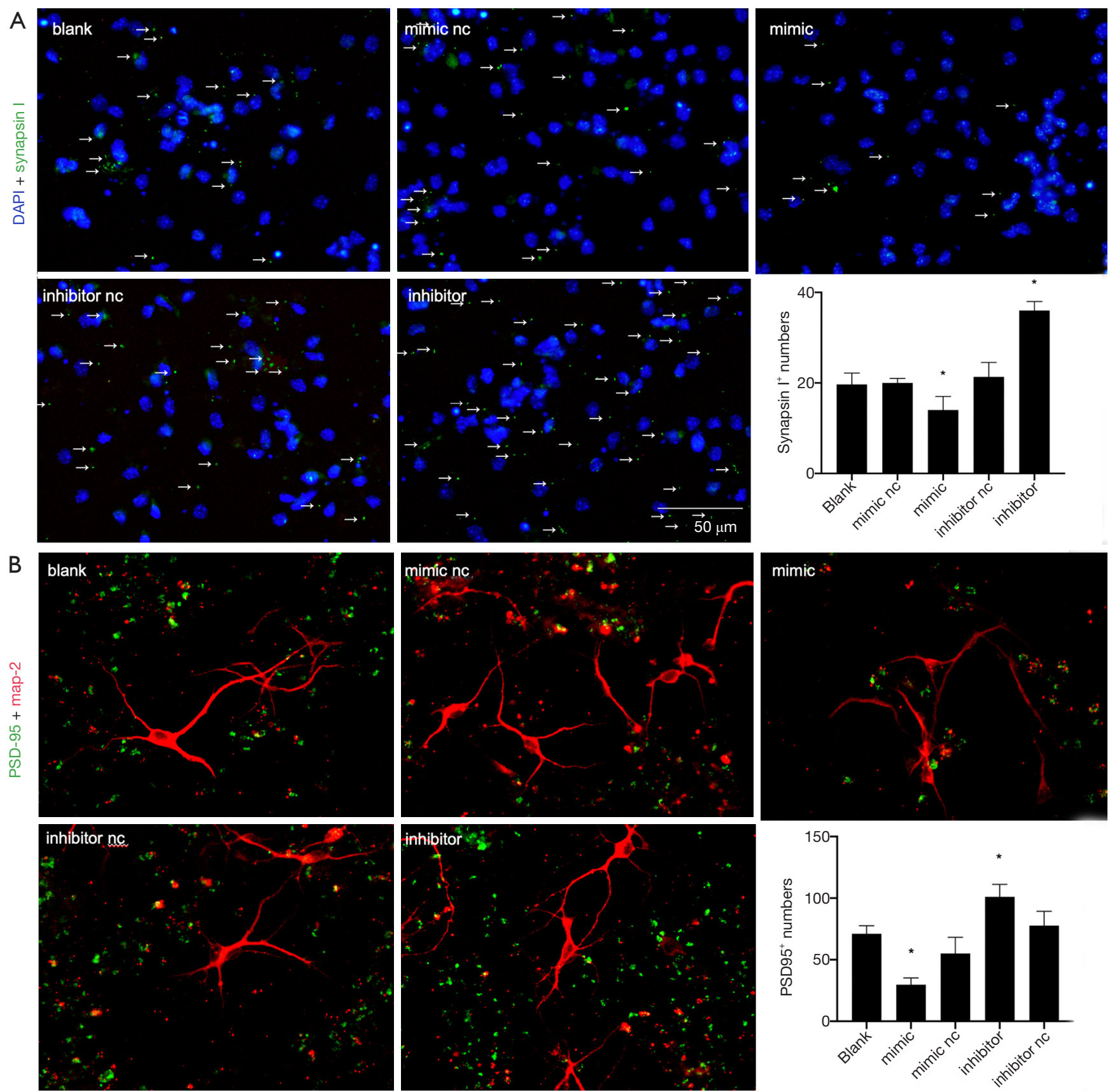

Figure 6 MiR-140-5p overexpression inhibited the expression of synapse-associated proteins after differentiation. (A) 4,6-diamino-2-phenyl indole (DAPI) (blue) and Synapsin I (green) result in the five groups after 7-day differentiation. The arrow markers represent Synapsin I+ cells (B) PSD-95 (green) and MAP-2 (red) result in the five groups after 7-day differentiation. Data are presented as the mean \pm SEM $\left({ }^{*} \mathrm{P}<0.05\right)$. Bar $=50 \mu \mathrm{m}$. 

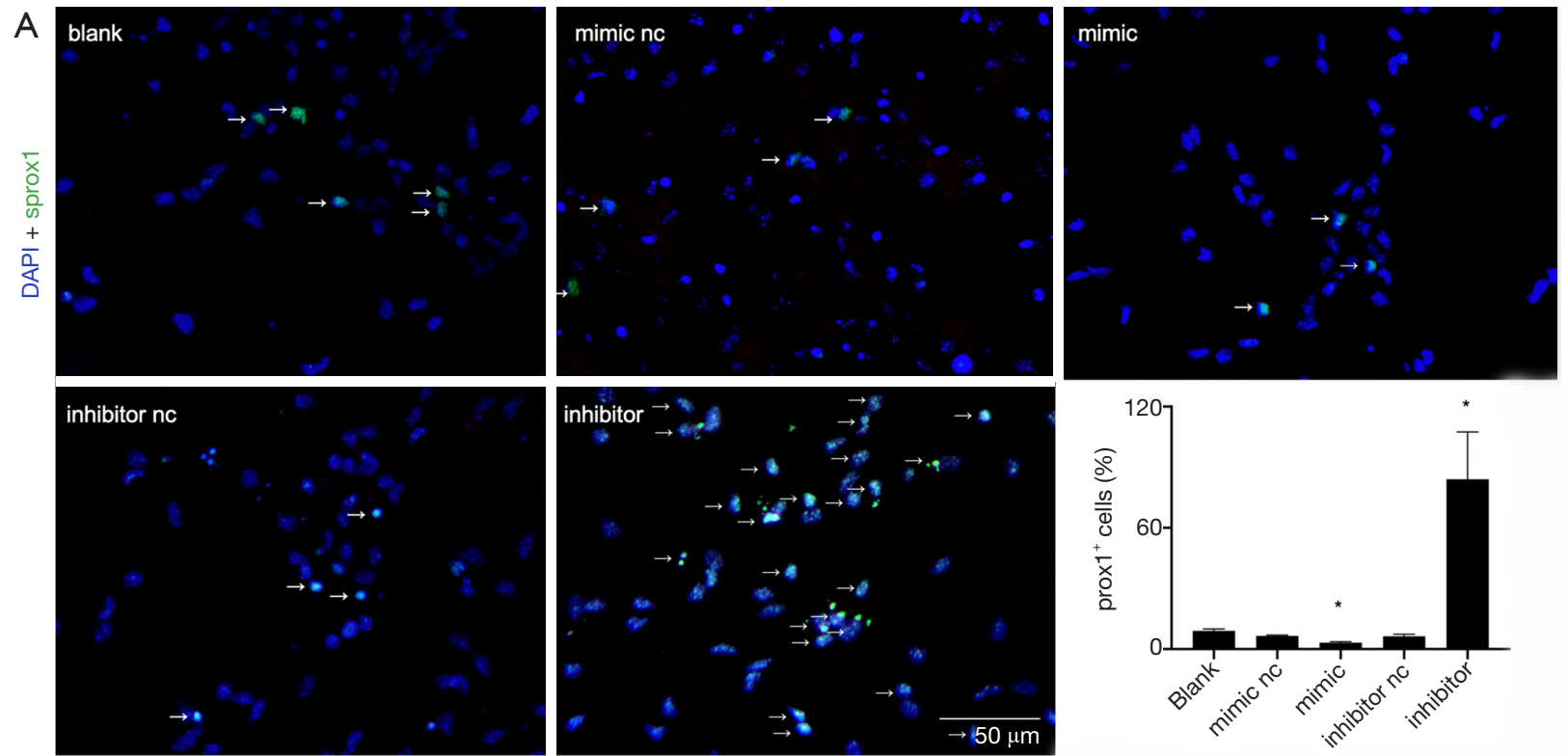

B

C
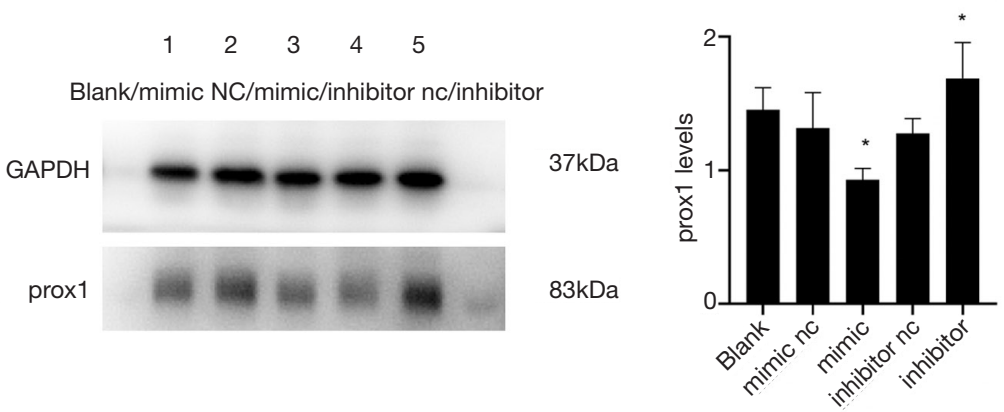

Figure 7 Overexpression of miR-140-5p inhibited the downstream target of transcription factor Prox1. (A) Immunofluorescence result of 4,6-diamino-2-phenyl indole (DAPI) (blue) and Prox1 (red) in the five groups. The arrow markers represent Prox1+ cells. (B) The 3' noncoding region of PROX1 mRNA is completely complementary to the 6-nucleotide seed sequence at the 5' end of miR-140-5p, which is the predicted target site region. (C) Western blot analysis result of Prox1 in the five groups. Data are presented as the mean \pm SEM $\left({ }^{*} \mathrm{P}<0.05\right.$ ). Bar $=50 \mu \mathrm{m}$.

of newborn neurons in the adult mammalian brain, and these neurons form complex sensory and cognitive functions thereafter (13). Further, NSCs are generally in a quiescent state and can be activated under various stimuli and in brain injuries. The differentiation of NSCs is a complex and continuous process which sees them first differentiate into radial glia-like cells and then become intermediate precursor cells, which have bidirectional potential and the ability to differentiate into neurons or astrocytes (24).

Thirdly, miR-140-5p inhibited the generation of synaptic-associated proteins by NSCs. The synapses of neurons were connected to each other to form an intricate neural network, which is the structural and functional basis of neuronal information transmission in the brain (25). The integrity of synapses is considered to be the basis of learning and memory. The terminal of synapses contains many proteins involved in calcium transport, neurotransmission, signal transduction, synaptic growth, and synaptic plasticity and the expression of synapse-associated proteins is related to the efficiency of substance and information transmission. In summary, mir-140-5p inhibited the proliferation of NSCs and their differentiation into neurons and synapses $(26,27)$.

The inhibition of miR-140-5p can promote the differentiation of NSCs into neurons by increasing the content of Prox1, which is the key factor conducive to 

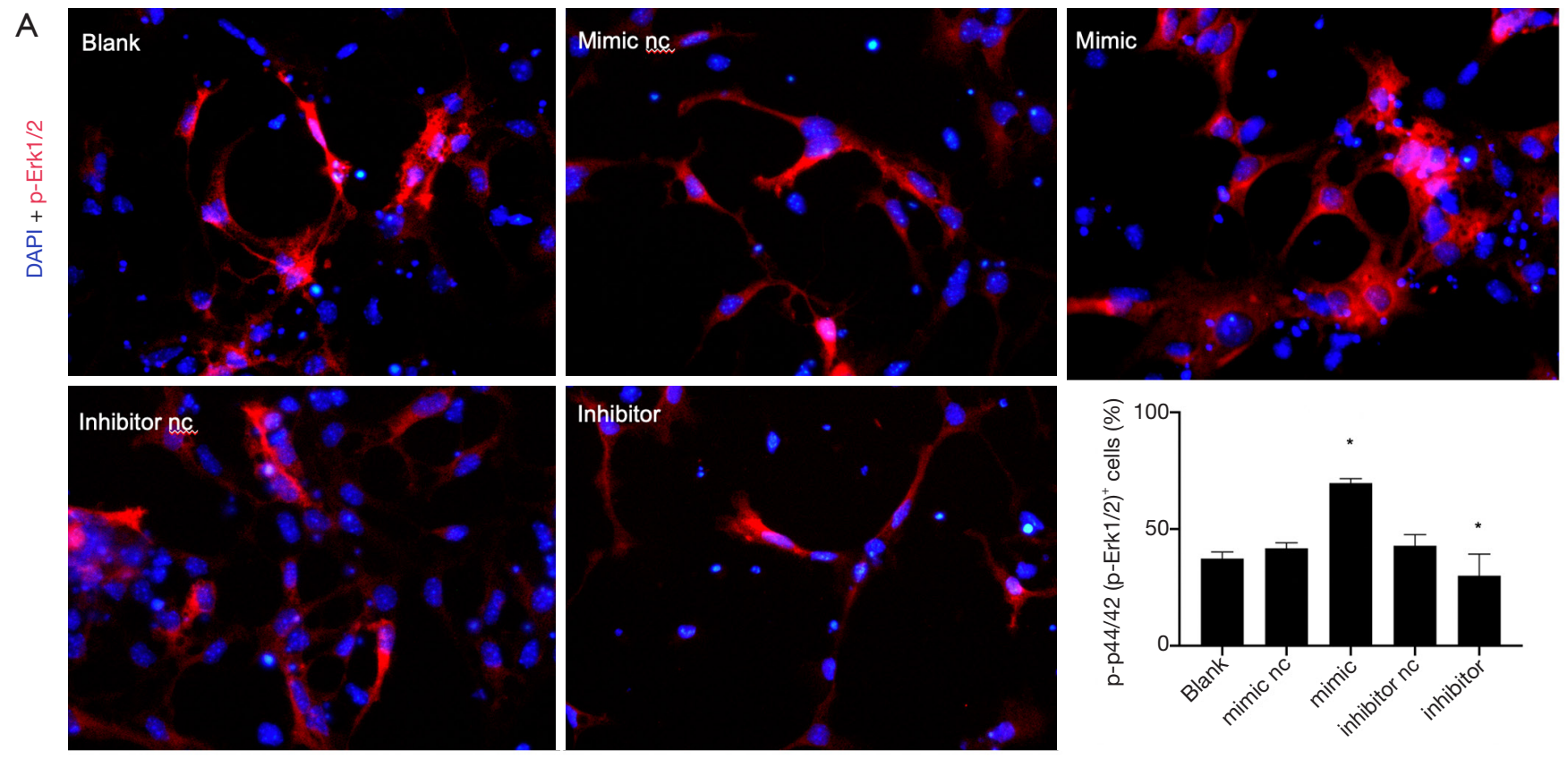

B
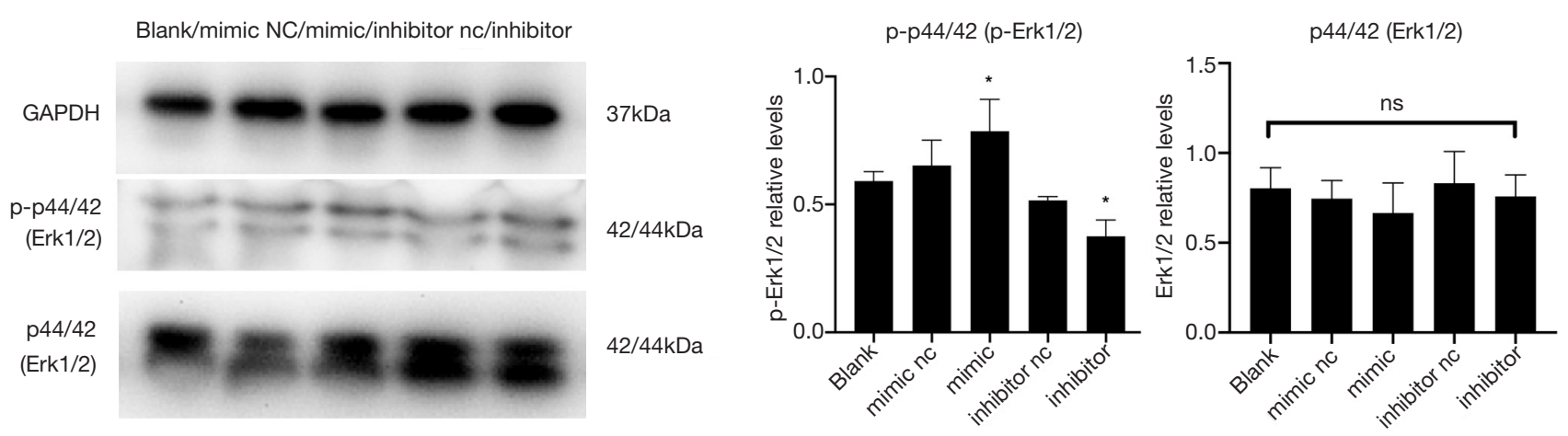

Figure 8 Overexpression of miR-140-5p activated the ERK/MAPK signaling pathway. (A) Fluorescence intensity of 4,6-diamino-2-phenyl indole (DAPI) (blue) and p-ERK1/ERK2 (red) in the five groups. (B) Western blot analysis result of p-ERK1/2 and ERK1/2. Data are presented as the mean $\pm \operatorname{SEM}\left({ }^{*} \mathrm{P}<0.05\right)$. Bar $=50 \mu \mathrm{m}$.

promoting neurogenesis in the brain, and it help recover nerve function after cerebral ischemia and hypoxia (19). While the role of Prox 1 in the development of the liver, pancreas, heart, lens, and lymphatic vessels has been reported in many studies, the significance of Prox 1 in developing the central nervous system has also gained attention in recent years. Prox 1 can control the generation of new granule neurons in the adult hippocampus under canonical Wnt signaling regulation (28) and prompt the cell cycle exit and differentiation of NSCs by inhibiting the Notch pathway (29). As the miR-140-5p downstream target, Prox1 is also important in promoting neurogenesis and NSC differentiation into neurons and highly expressed Prox1 can influence the MAPK pathway to promote the growth and extension of glial cell neurites in Drosophila (21). However, no studies have investigated how transcription factor Proxl influences the Erk/ MAPK signaling pathway in NSCs of mice. The Kyoto Encyclopedia of Gene and Genomes analysis of miR-140$5 \mathrm{p}$ showed that the targets were mainly enriched in the Ras/Raf-MEK-ERK MAPK pathway.

The results of this studies indicate downregulated Prox1 is involved in inhibiting neurogenesis by activating the ERK/MAPK signaling pathway in mice. ERK/ 
MAPK is a signaling pathway essential for cell growth and differentiation, and many human neurodevelopmental syndromes, such as macrocephaly, neurodevelopmental delay, cognitive impairment, and epilepsy, are related to abnormal ERK/MAPK activity (30). MAPK is a group of highly conserved serine/threonine protein kinases that can be activated by a series of extracellular stimulus signals and mediate signal transmission from the cell membrane to the nucleus. MAPK regulate many physiological activities, such as inflammation, apoptosis, invasion, and metastasis of tumor cells (31).

Therefore, miR-140-5p inhibited the proliferation and differentiation of NSCs into neurons by targeting Prox1 via activating the ERK/MAPK signaling pathway. Mir-140$5 \mathrm{p}$ can act as a good diagnostic and therapeutic biomarker because microRNA can be detected in the peripheral blood and have many downstream targets. Furthermore, miRNA is commonly expressed in the brain and has become one of the effective regulators in multiple processes of neurogenesis, including NSC proliferation, differentiation, and cell fate determination (32).

This means the inhibition of miR-140-5p is helpful in the recovery of neurological function and treatment for many central nervous diseases by promoting NSC differentiation into neurons. Nowadays, exogenous NSC transplantation is considered to hold great promise in curing a variety of brain illnesses. Some animal studies found that exogenous NSC transplantation improved the brain function of mice via intraventricular injection after stroke $(33,34)$. Clinical studies also proved that NSC transplantation had neuroprotective effects (35) and improved the neurological function of patients after stroke (36). Compared with vascular injection, intraventricular injection conveyed more NSCs to the infarct area, but as an invasive method was associated with more trauma (37). Although arterial injection is more effective than intravenous injection for intravascular transplantation, the risk of microthrombus formation is higher (38). Further, most NSCs remain in the lungs after intravenous injection. Therefore, methods to provide the safe and effective application of stem cell therapy requires further research.

The rate of neurogenesis in health adult mammals is very limited, and endogenous NSCs cannot provide enough cells to repair the pathological damage caused by central nervous diseases such as stroke (14). Only some NSCs transplanted into the brain can differentiate into neurons (36), which significantly limits the application. However, the inhibition of miR-140-5p can promote NSC differentiation, which improves the effectiveness of stem cell therapy. Despite this, the regulatory mechanism of NSCs is very complicated, including the method by which NSCs are injected, the part of the brain they are input into, and the induction of the proliferation, differentiation, and migration of NSCs to a specific part to perform functions $(36,38)$, and a significant amount of further research is required to fully understand these factors and the treatment of central nervous disease as a whole. This study explored the effect of miR-140$5 \mathrm{p}$ on NSCs under normal oxygen conditions. In future research an oxygen and glucose deprivation model (OGD) should be established to study how miR-140-5p regulates neurogenesis under hypoxic ischemia conditions.

\section{Acknowledgments}

The authors would like to thank LL Zeng for her guidance and ZH Lai for her help. They also thank Mr. Yang for providing a valuable laboratory platform and HB. Liang Huaibin completed the preliminary in vivo animal experiments. The authors also thank the laboratory partners for their experimental guidance.

Funding: This work was supported by the National Natural Science Foundation of China projects (81471246 to LZ).

\section{Footnote}

Reporting Checklist: The authors have completed the ARRIVE reporting checklist. Available at http://dx.doi. org/10.21037/atm-21-597

Data Sharing Statement: Available at http://dx.doi. org/10.21037/atm-21-597

Conflicts of Interest: All authors have completed the ICMJE uniform disclosure form (available at http://dx.doi. org/10.21037/atm-21-597). The authors have no conflicts of interest to declare.

Ethical Statement: The authors are accountable for all aspects of the work in ensuring that questions related to the accuracy or integrity of any part of the work are appropriately investigated and resolved. All animal experiments were performed in accordance with the guidelines for animal care and the research protocol for this study was approved by the Institutional Animal Care and Use Committee of Shanghai Jiao Tong University, Shanghai, China. 
Open Access Statement: This is an Open Access article distributed in accordance with the Creative Commons Attribution-NonCommercial-NoDerivs 4.0 International License (CC BY-NC-ND 4.0), which permits the noncommercial replication and distribution of the article with the strict proviso that no changes or edits are made and the original work is properly cited (including links to both the formal publication through the relevant DOI and the license). See: https://creativecommons.org/licenses/by-nc-nd/4.0/.

\section{References}

1. Altieri M, Maestrini I, Mercurio A, et al. Depression after minor stroke: prevalence and predictors. Eur J Neurol 2012;19:517-21.

2. Lu TX, Rothenberg ME. MicroRNA. J Allergy Clin Immunol 2018;141:1202-7.

3. Bushati N, Cohen SM. microRNA functions. Annu Rev Cell Dev Biol 2007;23:175-205.

4. Zhang Y, Cheng L, Chen Y, et al. Clinical predictor and circulating microRNA profile expression in patients with early onset post-stroke depression. J Affect Disord 2016;193:51-8.

5. Mirzaei H, Momeni F, Saadatpour L, et al. MicroRNA: Relevance to stroke diagnosis, prognosis, and therapy. J Cell Physiol 2018;233:856-65.

6. Bulygin KV, Beeraka NM, Saitgareeva AR, et al. Can miRNAs Be Considered as Diagnostic and Therapeutic Molecules in Ischemic Stroke Pathogenesis?-Current Status. Int J Mol Sci 2020;21:6728.

7. Cheng LC, Pastrana E, Tavazoie M, et al. miR-124 regulates adult neurogenesis in the subventricular zone stem cell niche. Nat Neurosci 2009;12:399-408.

8. Zeng L, Liu J, Wang Y, et al. MicroRNA-210 as a novel blood biomarker in acute cerebral ischemia. Front Biosci (Elite Ed) 2011;3:1265-72.

9. Liang HB, He JR, Tu XQ, et al. MicroRNA-140-5p: A novel circulating biomarker for early warning of late-onset post-stroke depression. J Psychiatr Res 2019;115:129-41.

10. Vieira MS, Santos AK, Vasconcellos R, et al. Neural stem cell differentiation into mature neurons: Mechanisms of regulation and biotechnological applications. Biotechnol Adv 2018;36:1946-70.

11. Faigle R, Song H. Signaling mechanisms regulating adult neural stem cells and neurogenesis. Biochim Biophys Acta 2013;1830:2435-48.

12. Xing L, Larsen RS, Bjorklund GR, et al. Layer specific and general requirements for ERK/MAPK signaling in the developing neocortex. Elife 2016;5:e11123.

13. Urbán N, Blomfield IM, Guillemot F. Quiescence of Adult Mammalian Neural Stem Cells: A Highly Regulated Rest. Neuron 2019;104:834-48.

14. Boese AC, Le QE, Pham D, et al. Neural stem cell therapy for subacute and chronic ischemic stroke. Stem Cell Res Ther 2018;9:154.

15. Hao L, Zou Z, Tian H, et al. Stem Cell-Based Therapies for Ischemic Stroke. Biomed Res Int 2014;2014:468748.

16. Takagi $Y$, Nishimura M, Morizane A, et al. Survival and differentiation of neural progenitor cells derived from embryonic stem cells and transplanted into ischemic brain. J Neurosurg 2005;103:304-10.

17. Irion S, Zabierowski SE, Tomishima MJ. Bringing Neural Cell Therapies to the Clinic: Past and Future Strategies. Mol Ther Methods Clin Dev 2016;4:72-82.

18. Ambros V. MicroRNAs and developmental timing. Current Opinion in Genetics \& Development 2011;21:511-7.

19. Stergiopoulos A, Elkouris M, Politis PK. Prospero-related homeobox 1 (Prox1) at the crossroads of diverse pathways during adult neural fate specification. Front Cell Neurosci $2015 ; 8: 454$.

20. Wigle JT, Chowdhury K, Gruss P, et al. Prox1 function is crucial for mouse lens-fibre elongation. Nat Genet 1999;21:318-22.

21. Griffiths RL, Hidalgo A. Prospero maintains the mitotic potential of glial precursors enabling them to respond to neurons. EMBO J 2004;23:2440-50.

22. Goldberg JL. How does an axon grow? Genes Dev 2003;17:941-58.

23. Bernstock JD, Peruzzotti-Jametti L, Ye D, et al. Neural stem cell transplantation in ischemic stroke: A role for preconditioning and cellular engineering. J Cereb Blood Flow Metab 2017;37:2314-9.

24. Bonaguidi MA, Wheeler MA, Shapiro JS, et al. In Vivo Clonal Analysis Reveals Self-Renewing and Multipotent Adult Neural Stem Cell Characteristics. Cell 2011;145:1142-55.

25. Scheff SW, Price DA, Schmitt FA, et al. Synaptic alterations in CA1 in mild Alzheimer disease and mild cognitive impairment. Neurology 2007;68:1501-8.

26. Li B, Wanka L, Blanchard J, et al. Neurotrophic peptides incorporating adamantane improve learning and memory, promote neurogenesis and synaptic plasticity in mice. FEBS Lett 2010;584:3359-65.

27. Leal G, Comprido D, Duarte CB. BDNF-induced local protein synthesis and synaptic plasticity. Neuropharmacology 2014;76 Pt C:639-56. 
28. Karalay O, Doberauer K, Vadodaria KC, et al. Prosperorelated homeobox 1 gene (Prox1) is regulated by canonical Wnt signaling and has a stage-specific role in adult hippocampal neurogenesis. Proc Natl Acad Sci U S A 2011;108:5807-12.

29. Kaltezioti V, Kouroupi G, Oikonomaki M, et al. Prox1 regulates the notch1-mediated inhibition of neurogenesis. PLoS Biol 2010;8:e1000565.

30. Rauen KA. The RASopathies. Annu Rev Genomics Hum Genet 2013;14:355-69.

31. Whelan JT, Hollis SE, Cha DS, et al. Post-transcriptional regulation of the Ras-ERK/MAPK signaling pathway. J Cell Physiol 2012;227:1235-41.

32. Nampoothiri SS, Rajanikant GK. Decoding the ubiquitous role of microRNAs in neurogenesis. Mol Neurobiol 2017;54:2003-11.

33. Oki K, Tatarishvili J, Wood J, et al. Human-Induced Pluripotent Stem Cells form Functional Neurons and Improve Recovery After Grafting in Stroke-Damaged Brain. STEM CELLS 2012;30:1120-33.

Cite this article as: Ding K, Lai Z, Yang G, Zeng L. MiR-140$5 p$ targets Prox 1 to regulate the proliferation and differentiation of neural stem cells through the ERK/MAPK signaling pathway. Ann Transl Med 2021;9(8):671. doi: 10.21037/atm-21597
34. Takagi Y. History of Neural Stem Cell Research and Its Clinical Application. Neurol Med Chir(Tokyo) 2016;56:110-24.

35. Jin K, Mao X, Xie L, et al. Transplantation of Human Neural Precursor Cells in Matrigel Scaffolding Improves Outcome from Focal Cerebral Ischemia after Delayed Postischemic Treatment in Rats. J Cereb Blood Flow Metab 2010;30:534-44.

36. Pendharkar AV, Chua JY, Andres RH, et al. Biodistribution of Neural Stem Cells After Intravascular Therapy for Hypoxic-Ischemia. Stroke 2010;41:2064-70.

37. Savitz SI, Dinsmore J, Wu J, et al. Neurotransplantation of Fetal Porcine Cells in Patients with Basal Ganglia Infarcts: A Preliminary Safety and Feasibility Study. Cerebrovasc Dis 2005;20:101-7.

38. Chua JY, Pendharkar AV, Wang N, et al. Intra-Arterial Injection of Neural Stem Cells using a Microneedle Technique does not Cause Microembolic Strokes. J Cereb Blood Flow Metab 2011;31:1263-71. 